\title{
Direito, ciência e educação: uma observação sistêmica da (re)produção do conhecimento
}

Law, science and education: a systemic observation of (re)production of knowledge

\author{
Giselle Marie Krepsky1 ${ }^{(D)}$ e Ana Paula Pianezer Tank² \\ ${ }^{1}$ Universidade Regional de Blumenau (FURB) e doutora em Direito Público, emaill: gkrepsky@ furb.br \\ ${ }^{2}$ Universidade Regional de Blumenau (FURB) e bacharela em Direito, email: anapaulapianezer@ hotmail.com
}

\section{RESUMO}

Este artigo apresenta uma observação sobre a correlação entre a produção acadêmico-científica Stricto Sensu em Direito e em Educação (Ensino Jurídico) e os Cursos de Graduação em Direito de Santa Catarina e suas possíveis influências no Sistema do Direito. A partir da teoria sistêmica de Niklas Luhmann e releituras contemporâneas e da análise textual discursiva das produções acadêmico-científicas, perfis profissiográficos, objetivos e das matrizes curriculares dos Cursos de Direito de Santa Catarina evidenciouse que as comunicações científicas sobre o Ensino Jurídico e sobre o Direito são pouco observadas pelo Sistema da Educação. Além disso, o que se produz cientificamente sobre o Direito, embora com variação temática e superando a observação dogmática, mostra-se insuficiente para provocar uma irritação no sistema do Direito, porquanto esta se mantém reproduzindo no sistema jurídico. Conclui que os três Sistemas compõem uma complexa relação de autorreprodução dificultando a superação do status quo acadêmico e jurídico.

Palavras-chave: Sistema jurídico. Ciência e educação. (Re)produção do conhecimento.

\section{ABSTRACT}

This article presents an observation about the correlation between academic-scientific production Stricto Sensu in Law and Education (Law Education) and undergraduate courses in Law of Santa Catarina and its possible influences on the Law System. From the systems theory of Niklas Luhmann and contemporary reinterpretations and discursive textual analysis of the academic and scientific productions, professional profiles, goals and curriculum matrices of Santa Catarina Law Schools, it was evident that the scientific communications about Legal Education and about Law are rarely observed by the Education System. Moreover, what is scientifically produced about Law, although with thematic variation and overcoming the dogmatic observation, it shows insufficient to cause irritation in the Law System, because it remains reproducing the Legal System. Concludes that the three systems compose a complex relationship selfreproduction making it difficult to overcome the academic and legal status quo.

Keywords: Law System. Science and education. (Re)production of knowledge. 


\section{INTRODUÇÃO}

Este artigo tem como fenômeno investigativo a produção do conhecimento científico sobre o Direito e sobre a Educação Jurídica e sua relação com os Cursos de Graduação em Direito de Santa Catarina. Partiu-se do pressuposto de que há um ciclo de reprodução entre a Educação e o Direito que pode ser fomentado tanto pelo Sistema da Educação (Jurídica) quanto pelo Sistema da Ciência (produção acadêmico-científica). Afinal, para os três sistemas nos quais estas comunicações sociais estão inseridas: Direito, Ciência e Educação, tem se delegado a responsabilidade de efetivar a transformação social. Assim, o objetivo da pesquisa foi observar se há correlação entre a produção acadêmico-científica Stricto Sensu em Direito e em Educação (Ensino Jurídico) e os Cursos de Graduação em Direito de Santa Catarina, bem como o nível de reprodução acadêmico-científica nestas áreas do conhecimento.

Devido à necessidade de se investigar e observar o fenômeno sócio-jurídico a partir dos subsistemas eleitos, o método pelo qual se norteou a pesquisa foi o sistêmico. A análise foi aportada na matriz pragmático-sistêmica de Niklas Luhmann, para quem a sociedade é, sobretudo, comunicação, e suas releituras contemporâneas, como a de Giancarlo Corsi (2002) que trata da capacidade de aprendizagem dos Sistemas Educativos e de Karl Eberhard Schorr (1993) com quem Luhmann estudou o Sistema da Educação. Isso porque se faz necessária a compreensão da tríade: Direito, Ciência (produção científica) e Educação (jurídica), como subsistemas que compõem o sistema social que é um complexo de elementos em interação. A priori, é preciso esclarecer que, do ponto de vista sistêmico, há diferenciação entre o sistema e seu entorno e nenhum sistema pode operar fora de seus limites (operação/observação). Esse é o ponto de partida para a teoria dos sistemas de Luhmann. Para Corsi, Esposito e Baraldi (1996, tradução nossa), sem um ambiente do qual se distingue também não seria possível identificar um sistema. Portanto, o sistema é uma área autônoma em que regem condições específicas (autopoiesis).

Portanto, necessita-se examinar os três sistemas de forma a não observá-los em isolamento sistêmico justamente para analisar a comunicabilidade e interferência existente entre eles e onde deverá ser o principal lócus de ajuste. Para tanto, a pesquisa que serviu de aporte para este artigo utilizou o método sistêmico e as técnicas do conceito operacional e categorias, bem como a pesquisa bibliográfica e documental além de contar com a metodologia Análise Textual Discursiva (ATD) de Moraes e Galiazzi (2007) de modo que fosse possível alcançar unidades de sentido para a construção do corpus textual para a análise dos dados.

Ciências Sociais Aplicadas em Revista, v. 20, n. 38, p. 78-93, semestral, janeiro-junho, 2020. 


\section{DIREITO, CIÊNCIA E EDUCAÇÃO COMO SISTEMAS AUTOPOIÉTICOS}

Todo ambiente (sociedade global) possui diferenciação de seus elementos em sistemas e subsistemas, que serve para estabilizar o meio uma vez que o sistema só consegue manter seus próprios limites se é capaz de observá-los e, portanto, de reproduzir em cada uma de suas operações a distinção entre si mesmo e o ambiente distinguindo o que propriamente lhe pertence do que pertence ao meio (TRINDADE, 2008). Isso é o que caracteriza um sistema autopoiético ("auto" que se refere ao próprio objeto e "poiese" que diz respeito à reprodução/criação). Portanto, para Luhmann, um sistema autopoiético é aquele que possui a capacidade de produzir e reproduzir os elementos que o constituem, e definir, assim, a sua própria unidade (CORSI, 2002).

Cumpre salientar que embora os sistemas autopoiéticos sejam operacionalmente fechados e, portanto, dotados de códigos próprios para manter sua unidade, eles são cognitivamente abertos para poder observar a sua diferença constitutiva e também do meio a fim de proporcionar sua manutenção (reprodução) e evolução (ROCHA, 2013). Esta característica permite a eles emitirem informações e se observarem.

O Sistema do Direito é um sistema funcional diferenciado, cuja função é manter estáveis as expectativas sociais ainda que resultem em vão. Essas expectativas são normas que permanecem estáveis independentemente de sua eventual violação. O Código que orienta o Direito está constituído pela diferença binária legal/ilegal, ou seja, existe comunicação jurídica toda vez que, em caso de controvérsia, alguém reivindica direitos e, em referência às normas vigentes, deve buscar decidir quem tem a razão da legalidade e quem não tem. O Sistema da Ciência opera com base no meio de comunicação da verdade. O código a que a verdade se refere para produzir comunicações é a distinção entre o verdadeiro e o não verdadeiro: esses dois valores qualificam como científica qualquer comunicação observável com base neles (CORSI; ESPOSITO; BARALDI, 1996).

No que se refere ao Sistema da Educação, sua função é induzir modificações nos sistemas psíquicos particulares, ou seja, através dele, possibilita-se que as pessoas (sistemas psíquicos) adquiram habilidades suficientes para se comunicarem na sociedade, exercendo seus papéis de acordo com diferentes profissões e em diferentes subsistemas sociais, porque uma das funções do Sistema da Educação também é formar para carreiras.

Assim, Corsi, Esposito e Baraldi (1996) salientam que a particularidade do Sistema Educativo está no fato de que ele não tem a função primária de elaborar uma comunicação como

Ciências Sociais Aplicadas em Revista, v. 20, n. 38, p. 78-93, semestral, janeiro-junho, 2020. 
os demais sistemas. Ele não tem a função de comunicar, de efetivamente obter "êxito educativo", mas essencialmente de propiciar mudanças nos sistemas psíquicos da sociedade. Dessa forma, o efeito da Educação se manifesta principalmente na capacidade e na consciencia dos individuos que precisam ter a competencia para participar da comunicação.

Desse modo, a função do Sistema da Educação é do tipo não primária, ou seja, é como uma função indireta de atuação e de interferência nos demais sistemas, porque interfere nos sistemas psíquicos que vão circundar o meio e que vão assumir papéis em outros sistemas e neles participar da comunicação. Por conta dessa particularidade, o sistema da Educação não tem um código próprio, embora tenha algo que se aproxime desse código que seria o estar apto ou não apto, hábil ou não hábil, mas, em tese, não tem código, já que não é possível codificar aquilo que é externo à sociedade. Assim, o que o Sistema da Educação possui são programas ao invés de códigos, os quais servem para propiciar o desenvolvimento de sistemas psíquicos.

Nesse sentido,

\begin{abstract}
Aunque la actividad educativa, al contrario del proceder selectivo, no puede ser codificada, tal educación debe proceder a programarla. Los programas en el sistema educativo (v. programa) consisten fundamentalmente en alcanzar estados psíquicos mediante intervenciones $a d$ hoc, por ejemplo el curriculum. Pero este logro sólo puede ser alcanzado mediante la forma de selección a través de los certificados, los titules, las calificaciones... que pueden ser obtenidos siempre y cuando el alumno manifieste logros correspondientes. Los estados psíquicos que se deben alcanzar son programas que se proponen un fin, pero aquello que se debe alcanzar, en todas sus formas, adquiere el carácter de programas condicionales. (CORSI; ESPOSITO; BARALDI, 1996, p. 72).
\end{abstract}

Então, as teses e dissertações são comunicações do Sistema da Ciência e os Cursos de Direito com suas matrizes e perfis profissiográficos fazem parte do Sistema da Educação enquanto programas.

Logo, pensar em mudança social por meio do Direito exige que este Sistema se coloque em abertura cognitiva para com o seu meio, ou seja, que ele seja capaz de observar o seu meio incluindo os demais sistemas que nele estão e o que comunicam, podendo dessa forma causar irritações capazes de produzir diferenças e, portanto, alterações. Desse modo, é necessário verificar: 1) se o que se está produzindo nos Programas de Pós-graduação é útil para as decisões do Direito e para a Educação Jurídica; 2) se os profissionais formados pela Educação Jurídica estão aptos para as complexidades sociais e; 3 ) se as mudanças curriculares e métodos de ensino são suficientes para alterar o ciclo de reprodução de conhecimento se realmente constatado. 
Por conta disso, relevante verificar como o Sistema do Direito vem se (re)produzindo com base nas observações que realiza. Isso inclui uma análise das produções científicas bem como das matrizes curriculares dos cursos, porquanto a educação jurídica exerce um papel fundamental em meio ao contexto de (re)produção do conhecimento jurídico. O Sistema da Educação, ao se voltar mais para as carreiras profissionais, fortalece o nexo entre o objeto da educação, a escolha de seus conteúdos e a possibilidade de transferir seus resultados. Por isso, ela não possui um fim em si mesma, mas é um pressuposto de cooperação entre os sistemas. (AUTOR; ROCHA, 2013). Assim, se constatado um nível de reprodução do conhecimento na Educação Jurídica, esse percorrerá todos os subsistemas em análise.

O novo conhecimento para atender aos novos e emergentes direitos em um meio sabidamente em processo de acelerada complexificação deve ser produzido levando-se em consideração as relações mediáticas e as inter-relações entre os subsistemas envolvidos e seus elementos constitutivos. Ou, como salienta Mascareño (2010, online): "Es necesaria una reorientación de la observación educativa desde la unidad hacia la diferencia, de modo tal que ella logre entender su relación com la complejidade [...]”.

\section{OBSERVANDO O ENSINO JURÍdico E A PRODUÇÃo CIENTífiCA COMO COMUNICAÇÕES SOCIAIS}

Para se alcançar os objetivos desta pesquisa, seguiram-se os seguintes passos metodológicos. Selecionou-se o número total de Instituições de Ensino Superior (IES) que ofertam Cursos de Graduação em Direito de Santa Catarina (SC). Foram identificadas 38 IES a partir do portal do $\mathrm{MEC}^{3}$, sendo que 01 delas foi excluída da amostra por constar como extinta ${ }^{4}$. Obteve-se o total de 67 Cursos. Desses, selecionou-se apenas os que foram avaliados no ENADE ${ }^{56}$, cujas informações também foram obtidas a partir do site do $\mathrm{MEC}^{7}$, totalizando 54 Cursos. A partir desse

\footnotetext{
${ }^{3}$ BRASIL. MEC. Instituições de Ensino Superior e Cursos Cadastrados. Disponível em: <http://emec.mec.gov.br/>. Acesso em: 10 ago. 2015. Selecionar estado de Santa Catarina $\rightarrow$ Curso Direito $\rightarrow$ Instituições.

${ }^{4}$ Faculdade Exponencial - Descredenciada (Parecer 144/2010 - CNE/CES).

${ }^{5}$ O Exame Nacional de Desempenho de Estudantes (Enade) avalia o rendimento dos concluintes dos cursos de graduação em relação aos conteúdos programáticos, habilidades e competências adquiridas em sua formação. O Enade é obrigatório e a situação de regularidade do estudante no Exame deve constar em seu histórico escolar. A primeira aplicação do Enade ocorreu em 2004 e a periodicidade máxima da avaliação é trienal para cada área do conhecimento. Cf. INEP. Disponível em: <http://portal.inep.gov.br/enade>. Acesso em: 29 jun. 2019.

${ }^{6}$ Considerou-se a avaliação do Exame de 2012, porquanto a amostra de todas as fontes era possível fazer o cruzamento de dados.

${ }^{7}$ BRASIL. MEC. Instituições de Ensino Superior e Cursos Cadastrados. Disponível em: <http://emec.mec.gov.br/>. Acesso em: 10 ago. 2016. Entre as notas obtidas, $4 \%$ são referentes ao ano de $2009,81 \%$ referentes ao ano de 2012 e $15 \%$ das IES não apresentaram conceito por causas desconhecidas. Para esta pesquisa, as IES que não apresentaram conceitos ou cujas notas, no Enade, referiam-se ao ano de 2009, foram desconsideradas.
} 
exame, pode-se verificar que nem todos os cursos apresentaram bom resultado. Entre eles, 19\% apresentaram notas iguais a $4 ; 57 \%$ notas iguais a 3; $17 \%$ notas iguais a 2 e $7 \%$ notas iguais a $1 . \mathrm{O}$ que levou à redução da amostra para os cursos que obtiveram conceituação igual a 4. A partir da próxima etapa, utilizou-se boa parte da técnica da Análise Textual Discursiva (ATD) proposta por Moraes e Galiazzi (2007) por meio da qual é possível extrair os sentidos de várias unidades de um texto extenso reunindo-os em categorias que o identifiquem de forma mais abrangente, sem, contudo, retirar-lhe o sentido.

Assim, analisaram-se os perfis profissiográficos e os objetivos dos referidos Cursos e percebeu-se que as suas maiores prioridades se referiam respectivamente a uma formação humanística (28\%), com articulação entre ensino, pesquisa e extensão (18\%), crítica e reflexiva $(5 \%)$, generalista (15\%), técnica (10\%), criativa e sensível (5\%), política (4\%) e com enfoque na mediação e meios de pacificação de conflitos (3\%). Essas características cumprem com o exigido pelas Diretrizes Curriculares Nacionais do Curso de Graduação em Direito prevista na Resolução CNE/CES nº 9, de 29 de setembro de 2004, do MEC, a qual prevê em seu artigo $3^{\circ}$ :

O curso de graduação em Direito deverá assegurar, no perfil do graduando, sólida formação geral, humanística e axiológica, capacidade de análise, domínio de conceitos e da terminologia jurídica, adequada argumentação, interpretação e valorização dos fenômenos jurídicos e sociais, aliada a uma postura reflexiva e de visão crítica que fomente a capacidade e a aptidão para a aprendizagem autônoma e dinâmica, indispensável ao exercício da Ciência do Direito, da prestação da justiça e do desenvolvimento da cidadania (BRASIL, 2004).

Ressalta-se que esta perspectiva foi corroborada pela Resolução CNE/CES n 05 de 17 de dezembro de 2018 em seu artigo $5^{\circ}$, como segue:

\begin{abstract}
O curso de graduação em Direito, priorizando a interdisciplinaridade e a articulação de saberes, deverá incluir no PPC, conteúdos e atividades que atendam às seguintes perspectivas formativas: I - Formação geral, que tem por objetivo oferecer ao graduando os elementos fundamentais do Direito, em diálogo com as demais expressões do conhecimento filosófico e humanístico, das ciências sociais e das novas tecnologias da informação, abrangendo estudos que, em atenção ao PPC, envolvam saberes de outras áreas formativas, tais como: Antropologia, Ciência Política, Economia, Ética, Filosofia, História, Psicologia e Sociologia. (BRASIL, 2018).
\end{abstract}

Ao estabelecer-se uma relação desses perfis e objetivos com as matrizes curriculares ${ }^{8}$ desses cursos identificou-se que as disciplinas enquadradas nas temáticas de "Direitos Humanos" (2\%),

\footnotetext{
${ }^{8}$ Extraídas dos sites oficiais de cada IES.
} 
"Linguagem" (9\%) e "Direito, inovação e tecnologia" (1\%) não estão entre as mais frequentes, embora sejam as temáticas mais presentes no que diz respeito ao perfil profissiográfico do egresso e os objetivos. As três temáticas que mais se destacaram foram: Direito e Estado (17\%), Sociedade e Conflito (14\%) e Processo (13\%). ${ }^{9}$ Esses percentuais indicam que o modelo de uma matriz curricular mais tecnicista e dogmática se mantém em dissonância com o que é pretendido pelos próprios Cursos de Graduação.

Interessante observar que, no âmbito das produções acadêmico-científicas, essas características persistem ao se analisar as teses produzidas pelos Programas de Direito no mesmo período, ${ }^{10}$ pois, daquelas observadas, o maior número de teses refere-se à temática "Direito, Estado e Constituição" (13\%). ${ }^{11}$ Assim, percebe-se uma consonância entre o que está no programa de formação acadêmico-jurídica - através das disciplinas presentes nas matrizes curriculares das IES listadas - com a produção científica que é comunicada pelos cursos Pós-graduação Stricto Sensu em Direito.

Já no que se refere às teses e dissertações que versam sobre o Ensino Jurídico comunicadas tanto pelos programas Stricto Sensu em Direito como em Educação ${ }^{12}$, constatou-se que a maior preocupação das pesquisas se concentra em metodologias e relações do Ensino Jurídico (35\%), sendo sucedidas pela preocupação com a pesquisa e a produção do Direito (18\%); docência jurídica (17\%); arte, humanismo e ética no ensino jurídico (12\%); crise e desafios do ensino jurídico (12\%); ensino jurídico e currículo (6\%).

Nesse contexto, observa-se que há uma indicação de que o ensino jurídico atual vem passando por complexos desafios, ou melhor, por uma crise estrutural. Afirma-se isso, porquanto

\footnotetext{
${ }^{9}$ Frequência completa das temáticas (ordem decrescente): Direito e Estado (17\%); Sociedade e Conflito (14\%); Processo (13\%); Direito, Sociedade e Cultura (10\%); Linguagem (9\%); Crime e Sociedade (8\%); Relações do trabalho e da empresa (7\%); Estágio de prática jurídica (7\%); Direito e relações internacionais (5\%); Direito e meio-ambiente (3\%); Direitos humanos (2\%); Trabalho de Curso (2\%); Direito, inovação e tecnologia (1\%), Direito aquaviário (percentual menor que 1\%). Frequência de disciplinas não consideradas por mesclaram áreas consideradas em separado para o processo de unidade da análise ou cuja ementa se encontrava indisponível para o processo de unitarização: $2 \%$.

${ }^{10}$ Essas teses correspondem aos programas Stricto Sensu em Direito (SC) com nota igual ou a 5 segundo a Capes do período de 01 janeiro de 2011 a 16 de dezembro de 2015.

${ }^{11}$ Frequência temática completa das teses comunicadas pelo sistema do Direito (ordem decrescente): Direito, Estado e Constituição $(13 \%)$; teóricos, teorias e metodologias $(9 \%)$; Direito e meio-ambiente $(7 \%)$; democracia, cidadania e participação $(6 \%)$; acesso à justiça e efetividade (5\%); Relações e cooperações internacionais (5\%), políticas públicas e gestão (5\%); processo (4\%); princípios (4\%); direitos humanos (4\%); direito e história (3\%); Bioética e biodireito (3\%); Direito e tecnologia (3\%); Posse e propriedade (2\%); Propriedade intelectual (2\%); Atuação Judicial (2\%); Saúde (2\%); Proteção crianças, adolescentes e jovens (2\%), Embrião e reprodução humana (2\%); Direito e educação (2\%); Direito e economia (2\%); Direito e trabalho (2\%); Crime e sociedade (2\%); Administração pública (2\%); Direito e comércio (2\%); Direito e solidariedade (2\%); Direito e seguridade (2\%); Direito e responsabilidade (1\%); Saber dos juristas (1\%); Igualdade de gênero (1\%); Educação (1\%); Tributação (1\%).

${ }^{12}$ Essas teses e dissertações correspondem aos programas Stricto Sensu em Direito e Educação (SC) com nota igual ou superior a 5 segundo a Capes do período de 01 janeiro de 2011 a 16 de dezembro de 2015.
} 
as teses e dissertações se ativeram principalmente ao estudo das metodologias e relações do Ensino Jurídico, as formas como o Direito vem sendo produzido, a necessidade de uma oxigenação curricular, incluindo-se ainda as características dos próprios docentes como fator contributivo da necessidade de reforma.

Tal diagnóstico se mostra relevante, já que uma das grandes vantagens do sistema da Educação é a possibilidade de obter resultados que sirvam para outros sistemas, ou seja,

La prestación que el sistema de educación proporciona a cada uno de los otros sistemas parciales de la sociedad consiste en el hecho de que éste vuelve accesible y de inmediato utilizable en su ambiente la selección que él mismo produce (LUHMANN; SCHORR, 1990, p. 291).

Então, o próprio Sistema da Educação pode exercer a prestação para o Sistema Social e seu subsistema do Direito a partir de um ensino mais humanista, mais ético e mais envolvido com a arte, confluindo na formação de um jurista mais crítico-sensível. Essa formação poderia e dar, inclusive, através de seu envolvimento constante com a pesquisa científica, o que vai ao encontro dos objetivos dos Cursos e dos perfis profissiográficos do egresso almejados por eles. Isto, aliás, vem ao encontro do que prevê o Código de Processo Civil de 2015 e todas os investimentos feitos pelo Sistema de Justiça no que se refere à pacificação dos conflitos, humanização da justiça, necessidade de conciliação e solução consensual de conflitos jurídicos.

Por outro lado, os dados evidenciaram uma contradição ao se observar que as matrizes curriculares dos cursos de Direito são ainda muito restritivas quando comparadas com a variação temática proveniente das demais comunicações científicas sobre o Sistema do Direito. Pois, embora $13 \%$ delas tenha se concentrado em "Direito, Estado e Constituição", o restante mostrou-se bastante diversificado. Ou seja, as observações científicas (teses e dissertações) sobre o Direito em SC oferecem variação temática, são mais abrangentes e estão mais em consonância com a complexidade social contemporânea.

Então, os Cursos Jurídicos (Sistema da Educação) poderiam observar e colocar-se em aprendizagem com o que se comunica cientificamente tanto sobre o Direito quanto sobre o Ensino Jurídico, obtendo-se assim uma melhor prestação do Sistema da Ciência. E, ainda a partir do Sistema da Ciência, as inovações necessárias das quais tratam as pesquisas sobre o Ensino Jurídico poderiam advir exatamente do leque observacional da Ciência Jurídica. 


\section{EDUCAÇÃO, CIÊNCIA E DIREITO: RELAÇÕES SISTÊMICAS E A (RE)PRODUÇÃo DO CONHECIMENTO}

As matrizes curriculares orientam a formação do egresso e sua perspectiva acadêmica e social sobre Direito, Sistema no qual irão atuar. Assim, se o modelo de uma matriz dogmática e tecnicista se mantém, o perfil do operador do Direito será dotado das mesmas características. Nesse sentido:

[...] a Dogmática Jurídica enfrentou uma declarada crise em relação às exigências políticas, sociais e econômicas de nosso tempo. A princípio, ela limitou-se apenas a um posicionamento do jurista perante uma atitude profissional, que o obrigava a uma especialização constante, dado o tipo de formação recebida na sua Universidade. A questão, então, era somente de uma correção nas linhas de ensino e de adaptação às necessidades sociais emergentes. Hoje, porém, a crise chega até os fundamentos, ao seu potencial argumentativo, à sua práxis decisória, aos respectivos resultados produzidos conscientes ou inconscientemente e aos conteúdos de formação profissional. Em contraposição, nasce uma exigência crescente de conhecimento adequado da situação social do sistema jurídico e de sua práxis, com todas as suas consequências (FERRAZ JUNIOR, 2015, p. 3).

Desse modo, as Universidades possuem um papel de suma importância nesse contexto, pois nada substitui o seu potencial crítico, sua autonomia de pensamento, sua capacidade de pronunciamento, em tom argumentativo para a comunidade mais ampla, seu poder de disseminação da reflexividade, sua vocação por excelência de centro de criação, questionamento e crítica do mundo físico e social (e de si mesma). As universidades não podem simplesmente sucumbir à lógica do mercado e silenciar diante das injustiças e desigualdades engendradas pela lógica da acumulação a qualquer preço (MELLO; ALMEIDA FILHO; RIBEIRO, 2009).

Além disso, observa-se que as Universidades, típicas organizações de acordo com as características propostas pela teoria sistêmica, absorvem funções duplas porquanto inerentes aos Sistemas da Educação e da Ciência. Isso ocorre, pois as atividades de ensino e pesquisa seguem por vezes imbricadas e muitas vezes operacionalizam-se a partir de pessoas que as executam concomitantemente. Sabe-se que é a partir dos Programas de Pós-Graduação, que pertencem à estrutura das Universidades, que emanam as teses e dissertações produzidas sobre o Direito. Assim, o papel do professor por vezes é cumulado com o de pesquisador em determinada IES. Sua influência se duplica e as possibilidades de interferências se sobrecarregam.

Como o desenvolvimento de um sistema é o desenvolvimento de sua própria estrutura e a partir de seus próprios elementos, quaisquer interferências advindas do meio e, portanto, de outros 
sistemas, são consideradas irritações. Elas até podem causar uma modificação na estrutura do subsistema, fazendo com que este se desenvolva. No entanto, a forma como esse desenvolvimento vai ocorrer obedecerá à lógica ou estrutura interna do subsistema irritado, o que quer dizer que sempre haverá um filtro interno de cada sistema ao permitir que se assimile o novo, o diferente. Assim, qualquer novidade apresentada pelas comunicações científicas somente será assimilada pelo Sistema da Educação ou pelo Sistema do Direito, se, antes, essa informação adequar-se em suas estruturas. Nesse sentido, Teubner (1989, p. 116) destaca que:

\begin{abstract}
A evolução pode ser 'estimulada' mas jamais 'causada' directamente a partir do exterior, prosseguindo daí em diante uma lógica interna e própria de desenvolvimento - a lógica da autopoiesis. [...] as mudanças jurídico-legislativas não são o puro resultado dos interesses sociais que sucedem a reflectir-se de algum modo no 'écran' interno do próprio sistema jurídico. O mesmo vale para os processos de inovação da doutrina jurídica, onde as inovações científicas exteriores apenas possuem significado para o direito na medida em que sejam filtradas por 'critérios de relevância' jurídico-dogmáticos próprios.
\end{abstract}

Então, por mais que as comunicações científicas sobre o Direito e sobre o Ensino Jurídico contemplem certa inovação ou observação diferente do Direito e seu Ensino, tais comunicações parecem pouco "irritar"13 o Direito e a Educação (jurídica). Pois, conforme observado, as comunicações científicas sobre o Ensino Jurídico não se refletem nas matrizes curriculares dos Cursos de Graduação em Direito. Igualmente, o que vem sendo produzido cientificamente sobre o Direito, embora com diversidade e grande variação temática, não é capaz de causar irritação sistêmica suficiente no Direito e sua Dogmática. Portanto, não há como se falar em uma tentativa de alteração do status quo quando os Sistemas da Ciência, do Direito e da Educação pouco se observam ou colocam-se em abertura cognitiva e capacidade de aprendizagem com o que se comunica pelos demais sistemas com os quais estão em relação.

São estas relações, assim observadas, que permitem concluir que as próprias reproduções dos elementos de cada Sistema em parca observação do meio incluindo os demais sistemas, que propiciam a (re)produção do Direito pela Educação, ainda que o Sistema da Ciência propicie observações diferenciadas.

\footnotetext{
${ }^{13}$ Para Luhmann a irritação tem a ver com a capacidade de interferência intersistêmica.
} 


\section{OBSERVAR O DIFERENTE PARA REESTRUTURAR-SE: REFORMA NECESSÁRIA NO SISTEMA DA EDUCAÇÃO (JURÍDICA)}

Percebe-se que se modificaram as exigências com relação à prática profissional do jurista, mas o ensino do Direito parece não estar acompanhando essa evolução social. Isso interfere diretamente na visão dogmática do Direito, ou para dizer sistemicamente, na sua auto-observação. Por isso:

O Direito continua inerte, estacionado no tempo, não tendo, em muitas situações, superado o século XVIII, ainda reproduzindo a ideia de que a simples positivação dos ideais do liberalismo é suficiente para gerar democracia e que o positivismo é o modelo epistemológico adequado para a produção do conhecimento jurídico (RODRIGUES, 1995, p. 120).

As matrizes curriculares - entendidas como o programa de ensino de um curso de estudo, circunscritas a um objetivo - têm uma relação bem precisa com a sociedade e representam a verdadeira prestação do Sistema da Educação. Conforme assevera Corsi (2002), na realidade, a elaboração de uma nova matriz prepara o contexto educativo para uma nova fase de desenvolvimento para a sociedade, para mudanças nas exigências humanas, intelectuais e civis.

O sistema da Educação necessita (e com certeza também os outros sistemas nos quais as organizações formais são decisivas) passar por reformas para que possa evoluir, ou seja, para que possa ser capaz de - ao observar os demais sistemas e ao meio circundante - assimilar deles informações que lhe permitam alterações estruturais. Em vista disso, as matrizes curriculares assumem um papel indispensável para esse intento (CORSI, 2002). Por esse ângulo, ao realizar um estudo acerca das matrizes curriculares dos cursos de Direito ainda na década de 60, constatou-se que as faculdades passaram, essencialmente a partir desse período, a focar o processo educativo na transmissão de informações genéricas da legislação. Desse modo, iniciava-se um processo de ensino pautado na desarticulação do conhecimento do Direito em relação à sociedade, um ensino no qual se ampliavam as disciplinas dogmáticas e processuais e se excluíam as matérias de cunho mais humanista (SILVA, 2013). Observação esta que se estende até os dias atuais.

Todavia, as reformas no sistema educativo podem conduzir não só a uma melhora como também a um agravamento em seu estado anterior, pois através delas é que foram sendo acrescentadas, de modo contínuo, disciplinas profissionalizantes com a mesma denominação dos Códigos a que respeitam. Assim, o Direito Civil estuda o Código Civil, o Direito Penal estuda o Código Penal, o Direito Processual Civil estuda o Código de Processo Civil, o Direito do 
Consumidor estuda o Direito do Consumidor e assim por diante. No entanto, tudo isso sem qualquer questionamento acerca da política de produção das normas, dos efeitos da sua aplicação e, principalmente, de sua adequação em dado contexto socioeconômico (SILVEIRA; SANCHES, 2013). Ou seja, sem uma observação policontextural necessária para que ocorram evoluções bem sucedidas. A partir da proposta da policontexturalidade torna-se possível uma observação com a atribuição de novos sentidos do Direito (ROCHA, 2009).

Em vista disso, a Resolução CNE/CES N 9, em 2004 já exigia que os currículos devessem estabelecer relações do Direito com outras áreas do saber como a Antropologia, a Ciência Política, a Economia, a Ética, a Filosofia, a História, a Psicologia e a Sociologia; e que além do enfoque dogmático, o conhecimento e a aplicação dos estudos fossem sistematizados e contextualizados [e por que não, policontextualizados] bem como que existisse uma integração entre a prática e os conteúdos teóricos. No entanto, essa política de flexibilidade estimulada pela política oficial para o ensino jurídico parece não ter sido suficientemente aproveitada pelas IES. Não por outro motivo que a ênfase na formação prática asseverou-se na Resolução CNE/CES nº 05 de 2018. Percebe-se isso na observação dos dados construídos, porquanto muitas IES ainda incorporam a interdisciplinaridade e o ensino da prática jurídica de maneira compartimentalizada e limitada (GHIRARDI; FEBERBAUM, 2013).

Portanto, estimular a criatividade dos discentes através da ideia de flexibilidade da grade curricular significa também preparar um corpo de docentes comprometidos com estratégias metodológicas inovadoras e com titulação e dedicação acadêmica que os capacitem para a tarefa de planejamento e de execução de um novo projeto pedagógico de curso, no qual o espaço para a interação com a realidade deve ser pensado não só no que diz respeito às disciplinas jurídicas bem como em sua interdisciplinaridade com aquelas não jurídicas, ou seja, com os diversos policontextos. Mas isso exige que o Sistema da Educação observe o que está a comunicar o Sistema da Ciência sobre o ensino jurídico, além de observar também o que se produz cientificamente sobre o Direito, a fim de que se possa superar a visão meramente dogmática de produção do próprio Direito.

É por isso que Warat (2004, p. 366) já chamava a atenção para:

La actitud problematizadora en educación, claro está no podrá, ser nunca lograda por medio de los métodos tradicionales que colocan al alumno en una actitud exclusivamente pasiva, facilitadora de un aprendizaje de corte dogmático, de una visión ingenua del mundo u la sociedad. Una visión que dificulta el cambio e asegura la continuidad del orden dado.

Ciências Sociais Aplicadas em Revista, v. 20, n. 38, p. 78-93, semestral, janeiro-junho, 2020. 
Em vista disso, embora as inter-relações entre os subsistemas Direito, Educação e Ciência se mostrem como possibilidade de uma efetiva transformação social, são inúmeras as limitações. Isto porque existe uma auto-reprodução inerente a cada um deles, e que, mais do que mantê-los adaptado ao meio circundante e em funcionamento, ela também pode revelar um caráter limitador de modificações importantes já que não será qualquer irritação sistêmica que será assimilada pelo Sistema. O mesmo pode-se afirmar do Sistema do Direito, que, ao observar o que observa a Ciência a seu respeito, nem sempre estará suscetível a mudanças estruturais ou decisionais.

\section{CONSIDERAÇÕES FINAIS}

A pesquisa evidenciou uma complexa relação entre os Sistemas do Direito, da Ciência e da Educação que direcionam o campo de produção do conhecimento nos três sistemas e, por consequência, suas implicações enquanto comunicações sociais.

No plano dos programas dos Cursos de graduação em Direito do estado de Santa Catarina, nos últimos anos, há contradição entre a pretensa formação de seu profissional, tendo em vista que as matrizes curriculares dos cursos de Direito ao mesmo tempo em que confluem com as temáticas que mais vem sendo observadas cientificamente pelo Direito (mais tecnicistas e dogmáticas), contradizem com os perfis e objetivos desejados pelos Cursos para os futuros egressos das IES.

No mesmo viés, identificou-se dissonância entre as preocupações científicas sobre o Ensino Jurídico oriundas tanto dos Programas de Pós-Graduação em Direito quanto em Educação. Além disso, as próprias teses e dissertações que versam sobre o Ensino Jurídico possuem um nível de reprodução em si, ou seja, ao mesmo tempo em que esses estudos apresentam propostas, estas são repetitivas, devido a suas similaridades temáticas e escassa inovação. Conclui-se, então, que a reprodução mais Dogmática e Tecnicista do Direito é fomentada tanto pelas pesquisas quanto pelos Cursos, em que pese o desejo seja o de formação seja mais ampla, humanista e interdisciplinar. Isso porque, o atuante tanto no Sistema do Direito quanto no Sistema da Ciência, possui a mesma formação profissional.

Essa realidade também se observa nas matrizes curriculares, visto que os currículos se apresentam pouco inovadores, porquanto ainda refletem o pensamento de que a visão dogmática e tecnicista é a melhor escolha quanto ao modelo epistemológico para a produção do conhecimento jurídico. Além disso, o enrijecimento dessas matrizes compromete o sistema do Direito, tendo em 
vista que a sociedade está em constante e complexa transformação enquanto sistema social e, portanto, necessita ser observada de maneira crítica, reflexiva (sob diferentes sistemas que se observam) e não de forma estrita à releitura de manuais, priorizando-se a memorização de conhecimentos.

Por outro lado, importante destacar que o que se produz cientificamente sobre o Direito, embora ainda preponderantemente a partir de uma visão dogmática, possui uma variação temática em Santa Catarina capaz de propiciar uma observação diferenciada pelo Sistema da Educação e do Direito. É, pois, este Sistema, o que, coloca-se em vanguarda no que se refere aos temas de maior complexidade sócio-jurídica. Indica-se então, que novos caminhos de observar o que se produz cientificamente possam ser galgados, posto que da Ciência também se espera uma prestação para a evolução social.

A Educação Jurídica necessita, assim, observar o diferente para reformar sua estrutura e, neste movimento, ser capaz de irritar sistemicamente os demais sistemas que se colocam em acoplamento estrutural. Do mesmo modo, o Sistema da Ciência enquanto produtor de ciência jurídica, precisa também observar o diferente, para ser capaz de produzir ressonância tanto no Direito quanto na Educação. São então, subsistemas sociais que em relação e acoplamento precisam observar-se para promover suas co-evoluções de modo a passarem da reprodução para a produção do conhecimento jurídico.

\section{REFERÊNCIAS}

BRASIL. MEC. Instituições de Ensino Superior e Cursos Cadastrados. Disponível em: <http://emec.mec.gov.br/>. Acesso em: 10 ago. 2015.

BRASIL. MEC. Resolução CNE/CES n. 9, de 29 de setembro de 2004. Disponível em: <http://portal.mec.gov.br/cne/arquivos/pdf/rces09_04.pdf>. Acesso em: 18 jun. 2019.

BRASIL. MEC. Resolução CNE/CES n. 5, de 17 de dezembro de 2018. Disponível em: $<$ http://portal.mec.gov.br/index.php?option=com_docman\&view=download\&alias $=104111-$ rces005-18\&category_slug=dezembro-2018-pdf\&Itemid=30192>. Acesso em: 18 jun. 2019.

CORSI, Giancarlo. Sistemas que aprenden: estudo sobre la idea de reforma en el sistema de educación. México: Universidad Iberoamericana, 2002.

; ESPOSITO, Elena; BARALDI, Claudio. Glosario sobre la teoría Social de Niklas

Luhmann. Tradução de Miguel Romero Pérez, Carlos Villalobos: sob a direção de Javier Torres Nafarrate, 1996. 
FERRAZ JUNIOR, Tercio Sampaio. Função social da dogmática jurídica. 2. ed. São Paulo: Atlas, 2015.

GHIRARDI, José Garcez; FEFERBAUM, Marina (organizadores). Ensino do Direito em debate: reflexões a partir do $1^{\circ}$ Seminário Ensino Jurídico e Formação Docente. São Paulo: Direito GV, 2013.

INEP. ENADE. Disponível em: 〈http://portal.inep.gov.br/enade>. Acesso em: 29 jun. 2019.

AUTOR; ROCHA, Leonel Severo. O direito, a ciência e a educação: relações intersistêmicas e as respostas para os novos direitos. Conpedi, São Paulo, 2013, p. 211-229. Disponível em: <http://www.publicadireito.com.br/artigos/?cod=59accb9fe696ce55>. Acesso em: 18 jun. 2019.

LUHMANN, Niklas. SCHORR, Karl Eberhard. El sistema educativo: (problemas de reflexión). Tradução de Javier Torres Nafarrate (Coordenador). México: Universidad Iberoamericana, 1993.

Presupuestos estructurales de una pedagogía reformista: análisis sociológicos de la pedagogía moderna. Revista de educación, Madrid, 1990, n. 291.

MASCAREÑO, Aldo. Diferenciación y contingencia em América Latina. Santiago: Ed. Universidad Alberto Hurtado, 2010.

MORAES, Roque; GALIAZZI, Maria do Carmo. Análise textual discursiva. Ijuí: Ed. Unijuí, 2007.

MELlO, Alex Fiúza de; ALMEIDA FILHO, Naomar; RIBEIRO, Renato Janine. Por uma Universidade socialmente relevante. Disponível em: <http://portal.mec.gov.br/dmdocuments/cne_alexfiuza.pdf>. Acesso em: 28 jun. 2019.

ROCHA, Leonel Severo. Da epistemologia jurídica normativista ao construtivismo sistêmico II. In: ROCHA, Leonel Severo; SCHWARTZ, Germano; CLAM, Jean. Introdução à teoria do sistema autopoiético do direito. Porto Alegre: Livraria do Advogado, 2005, p. 9-47.

Observações sobre a observação Luhmanniana. In: ROCHA, Leonel Severo; SCHWARTZ, Germano; KING, Michael. A verdade sobre a autopoiese no direito. Porto Alegre: Livraria do Advogado, 2009, p.11-40.

RODRIGUES, Horácio Wanderley. Novo currículo mínimo dos cursos jurídicos. São Paulo: Revista dos Tribunais, 1995.

SILVA, Bárbara Costa. Saberes propedêuticos e formação do bacharel em Direito no Brasil: (re)pensando a educação jurídica a partir da percepção dos docentes e discentes. 2013. 394 f.: II. Tese (Doutorado em Direito) - Programa de Pós-Graduação em Direito, Universidade do Vale do Rio dos Sinos, São Leopoldo, 2013.

SILVEIRA, V. O; SANCHES, S. H. D. F. N. A reprodução do paradigma dogmático da Ciência e do Direito no Ensino Jurídico e a Necessidade de Mudanças na Pesquisa Jurídica, que permita uma 
efetiva Educação Jurídica. In: SILVEIRA, V. O; SANCHES, S. H. D. F. N.; COUTO, M. B. (organizadores). Educação jurídica. São Paulo: Saraiva, 2013, p. 497-513.

TEUBNER, Gunther. O direito como sistema autopoiético. Tradução de José Engrácia Antunes. Lisboa: Fundação Calouste Gulbenkian, 1989.

WARAT, Luis Alberto. Educacion y Derecho. In: WARAT, Luis Alberto. Epistemologia e Ensino do Direito: O Sonho Acabou. Florianópolis: Fundação Boiteux, 2004.

TRINDADE, André Fernando dos Reis. Para entender Luhmann e o direito como sistema autopoiético. Porto Alegre: Livraria do Advogado Editora, 2008. 